
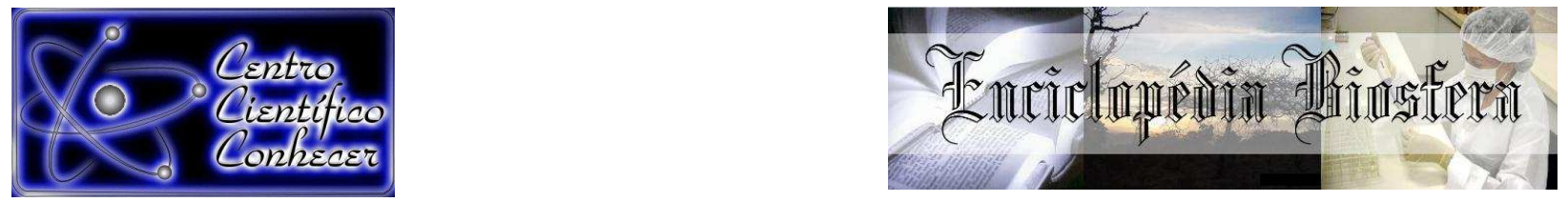

\title{
PRODUÇÃO DE BIOGÁS A PARTIR DA VINHAÇA: SIMULAÇÃO COMPUTACIONAL PARA REATOR UASB
}

\section{Eduardo Augusto Fabiano de Sousa ${ }^{1}$, Deusmaque Carneiro Ferreira ${ }^{2}$, Marcelo Bacci da Silva ${ }^{3}$}

1 Aluno de mestrado do PMPIT - UFTM

2 Professor Doutor do Programa de Pós-Graduação em Ciência e Tecnologia Ambiental da Universidade Federal do Triângulo Mineiro

3 Professor Doutor do PMPIT - UFTM(bacciuftm@gmail.com, UFTM - Universidade

Federal do Triângulo Mineiro, PMPIT - Programa de Mestrado Profissional em Inovação Tecnológica, Uberaba/MG)

Recebido em: 02/10/2017 - Aprovado em: 21/11/2017 - Publicado em: 05/12/2017 DOI: 10.18677/EnciBio_2017B118

Nas usinas sucroalcooleiras, a cana-de-açúcar é processada para produção de álcool e açúcar. A vinhaça é um subproduto da produção de álcool que, além de ser rica em nutrientes minerais, possui potencial para geração de biogás devido ao seu alto teor de matéria orgânica. Uma das alternativas existentes é a produção de biogás (metano) por meio do processo de biodigestão anaeróbia da vinhaça em reatores de manta de lodo UASB (Upflow Anaerobic Sludge Blanket). O biogás, assim produzido, apresenta potencial energético competitivo com outras fontes renováveis de energia, sendo a quantidade produzida relacionada às características da vinhaça e das configurações do reator de manta de lodo. O objetivo do presente estudo consistiu no desenvolvimento de um programa computacional capaz de simular o processo realizado no reator UASB para geração de biogás a partir da vinhaça. As equações de balanço de massa foram implementadas no programa para descrever a operação do reator UASB. Essas equações foram resolvidas com 0 propósito de estabelecer o volume de biogás produzido a partir de uma massa conhecida de vinhaça. Através de um planejamento fatorial foram analisadas as influências da $\mathrm{DQO}, \mathrm{DBO}_{5}$, vazão do afluente de vinhaça e da temperatura no volume de biogás produzido. Os resultados obtidos mostraram que todas as variáveis analisadas foram significativas para a produção de biogás. Portanto, por meio de uma simulação computacional obtêm-se informações úteis para a tomada de decisões quanto à instalação e à viabilidade econômica da produção de energia elétrica a partir da vinhaça.

PALAVRAS-CHAVE: Biogás; Vinhaça; Reator UASB. 


\title{
BIOGAS PRODUCTION FROM VINASSE: COMPUTATIONAL SIMULATION OF THE UASB REACTOR
}

\begin{abstract}
Sugarcane is processed in the sugar and ethanol plants to produce alcohol and sugar. Vinasse is a by-product of alcohol production that, in addition to being rich in mineral nutrients, has potential for biogas generation due to its high organic matter content. One of the existing alternatives is the production of biogas (methane) through the process of anaerobic biodigestion of vinasse in UASB sludge blanket reactors (Upflow Anaerobic Sludge Blanket). The biogas thus produced has a competitive energy potential with other renewable sources of energy, the amount produced being related to the characteristics of the vinasse and the configurations of the sludge blanket reactor. The objective of the present study was to develop a computer program capable of simulating the process performed in the UASB reactor to generate biogas from the vinasse. The mass balance equations were implemented in the program to describe the operation of the UASB reactor. These equations were solved for establishing the volume of biogas produced from a known mass of vinasse. Through a factorial planning the influences of $\mathrm{COD}, \mathrm{BOD}_{5}$, vinasse affluent flow and temperature in the biogas volume produced were analysed. The results showed that all variables analysed were significant for biogas production. Therefore, through a computer simulation, information is obtained that is useful for making decisions regarding the installation and economic viability of electric energy production from vinasse.
\end{abstract}

KEYWORDS: Biogas; Vinasse; Reactor UASB.

\section{INTRODUÇÃO}

O cenário de escassez de recursos hidráulicos e térmicos coloca as usinas hidrelétricas do Brasil numa situação delicada, (AMATO, 2014). Os reservatórios das regiões Sudeste e Centro-Oeste são responsáveis por cerca de $70 \%$ da energia hidrelétrica gerada no país. Atualmente, os níveis dos reservatórios estão abaixo dos níveis dos reservatórios no ano de 2001, quando, devido à crise de apagão, o governo instituiu o plano de racionamento de energia (LUCON; GOLDEMBERG, 2009).

O racionamento de energia é um dos reflexos da crise financeira que afeta diversos países, criando uma oportunidade para reorganizar o sistema energético usando como base a eficiência, a maior participação das fontes renováveis e a descentralização da produção de energia. Neste contexto, uma das alternativas para a crise energética atual seria a produção de energia por meio da cogeração em indústrias (RODRIGUES et al., 2012).

Atualmente, o Brasil é tido como uma potência sucroalcooleira global, sendo responsável por $25 \%$ da produção mundial de açúcar e por $20 \%$ da produção mundial de etanol. Segundo dados da União da Indústria de Cana-de-Açúcar (UNICA, 2017), a safra de 2015/2016 foi de 651.841 mil toneladas de cana-deaçúcar e foram produzidos mais de 27,25 milhões de $\mathrm{m}^{3}$ de etanol. As usinas sucroalcooleiras podem se tornar autossuficientes em relação à energia elétrica, pois aproveitam o bagaço, proveniente do processo de moagem da cana, para a geração de energia elétrica (REIN, 2017).

Existe ainda o potencial para aproveitamento da vinhaça para geração de 
biogás. A vinhaça é caracterizada como efluente de destilarias com alto poder poluente, riqueza em matéria orgânica e alto valor fertilizante, presença de macro e micronutrientes (REIN, 2017). Segundo Rodrigues et al. (2012), a geração de energia elétrica a partir do biogás apresentou viabilidade econômica em estudos realizados em criadouros de suínos de Santa Catarina. O biogás, ou gás metano, pode ser produzido a partir da vinhaça de cana-de-açúcar por meio da digestão anaeróbia em um reator do tipo UASB.

O reator UASB, também conhecido por reator de manta de lodo, foi desenvolvido para o tratamento de esgotos domésticos concentrados, sendo posteriormente também utilizado em esgotos de baixa concentração (CHERNICHARO, 2016). O Brasil e outros países de clima tropical já utilizam os reatores de manta de lodo para o tratamento de esgotos domésticos, conforme descrito por Moraes et al. (2014). As experiências bem-sucedidas nesses países indicam o potencial dos reatores de manta de lodo para o tratamento de águas residuárias.

O referido reator tem sido amplamente estudado devido à vantagem de combinar construção e operação simplificada com capacidade de acomodar altas cargas orgânicas volumétricas, com tempo de retenção hidráulica curto (RIZVI et al., 2015). Sua configuração é baseada no regime hidráulico de fluxo ascendente e na incorporação de um dispositivo interno de separação sólido/gás/líquido, o que dispensa o uso de um meio suporte para crescimento da biomassa, (CHERNICHARO, 2016).

A quantidade de biogás a ser produzido está relacionada às características da vinhaça e das configurações do reator de manta de lodo. As características da vinhaça variam de acordo com o tipo de mosto e outros fatores, tais como pureza da matéria-prima, concentração do etanol formado e quantidade de ácidos formados, (REIN, 2017).

Neste estudo, desenvolveu-se um programa computacional para simulação do processo realizado no reator UASB na geração de biogás a partir da vinhaça de cana-de-açúcar, que possibilitará a geração de resultados hipotéticos a partir dos valores informados sobre as características da vinhaça. O programa poderá ser usado para análise da viabilidade econômica da produção do biogás para geração de energia elétrica, fornecendo resultados para construção de um modelo concreto.

\section{MATERIAL E MÉTODOS}

A simulação da conversão de vinhaça em biogás foi feita a partir das equações utilizadas em projetos de reatores anaeróbios para tratamento de esgoto doméstico (CHERNICHARO, 2016). A vinhaça de cana-de-açúcar possui maior DQO e temperaturas mais elevadas quando comparada com o esgoto doméstico. A produção de biogás está diretamente ligada ao valor da DQO do efluente. Para a simulação, foi elaborado um programa de computador baseado no reator anaeróbio UASB, usando o código implementado em Object Pascal, com o programa Lazarus, que é uma IDE (Integrated Development Environment) multiplataforma, o mesmo pode ser executado em diferentes sistemas operacionais, como o Windows, Linux, Mac OS X, FreeBSD e outros, para desenvolvimento de aplicações (CANNEYT; KLAMPFL, 2012). Possui uma variedade de componentes prontos para uso e um formulário de designer gráfico que permite criar interfaces gráficas. A versão utilizada do Lazarus foi a \#:1.0.12 (CANNEYT; KLAMPFL, 2012). O simulador permite que os dados simulados sejam salvos em um histórico. Para a 
funcionalidade de histórico foi utilizado o banco de dados Firebird versão 2.5, que possui características padrão ANSI SQL. A plataforma para desenvolvimento utilizada foi o Sistema Windows de 32 bits.

Os parâmetros que devem ser informados são referentes às características da vinhaça, e este simulador utilizou os seguintes parâmetros:

- Vazão média do afluente em $\mathrm{m}^{3} / \mathrm{dia}$;

- Vazão máxima do afluente em $\mathrm{m}^{3} / \mathrm{dia}$;

- DQO do afluente em $\mathrm{mg} / \mathrm{L}$;

- Temperatura da vinhaça $\left({ }^{\circ} \mathrm{C}\right.$, imediatamente após a saída);

- Altura do reator em $\mathrm{m}$.

O programa computacional desenvolvido consiste de uma interface com duas abas. Na aba Simulação o usuário informa os parâmetros e as constantes necessários ao processo de simulação. A aba Histórico exibe o histórico dos parâmetros já utilizados para as simulações.

\section{Etapas da simulação}

A primeira etapa da simulação consiste em fornecer os parâmetros da vinhaça e das constantes pela interface do simulador. Abaixo são listados os nomes das variáveis que permitem identificar esses valores nas equações utilizadas pelo simulador:

- $Q_{\text {méd }}$ - Vazão afluente média $\left(\mathrm{m}^{3} / \mathrm{dia}\right)$;

- $Q_{\text {máx }}$ - Vazão afluente máxima $\left(\mathrm{m}^{3} / \mathrm{dia}\right)$;

- $\mathrm{DQO}_{\mathrm{so}}$ - DQO afluente inicial $(\mathrm{mg} / \mathrm{L})$;

- $\mathrm{DBO}_{\mathrm{so}}-\mathrm{DBO}_{5}$ afluente inicial $(\mathrm{mg} / \mathrm{L})$;

- $\mathrm{T}$ - Temperatura do afluente $\left({ }^{\circ} \mathrm{C}\right)$;

- Yabs - Coeficiente de produção de sólidos em termos de DQO (mg/L);

- TDH - Tempo de retenção hidráulica (h).

\section{a) Dimensionamento do reator UASB}

Para o dimensionamento do reator foi necessário o cálculo da carga média de DQO e do valor do TDH. O TDH consiste no tempo que o afluente deve permanecer dentro do reator, relação do volume $(V)$ do reator pela vazão $(Q)$ do afluente (vinhaça). O valor da carga média de DQO pode ser obtido pela Equação (1):

$$
D Q O_{L O}=D Q O_{S O} \cdot Q_{\text {méd }}
$$

Onde tem-se que:

$D Q O_{L O}$ - Carga média de DQO $(\mathrm{mg} / \mathrm{L})$;

$D Q O_{s o}-$ DQO do afluente de entrada $(\mathrm{mg} / \mathrm{L})$;

$Q_{\text {méd }}-$ Vazão média do afluente $\left(\mathrm{m}^{3} / \mathrm{dia}\right)$.

$\mathrm{O}$ TDH necessário ao processo depende da temperatura do afluente de acordo com a Tabela 1. 
TABELA 1 - Tempos de retenção hidráulica em reatores UASB.

\begin{tabular}{c|c|c}
\hline \multirow{2}{*}{ Temperatura $\left({ }^{\circ} \mathbf{C}\right)$} & \multicolumn{2}{|c}{ Tempo de retenção hidráulica $(\mathbf{h})$} \\
\cline { 2 - 3 } & Média diária & Mínimo (durante 4 a 6 h) \\
\hline $16-19$ & $>10-14$ & $>7-9$ \\
$20-26$ & $>6-9$ & $>4-6$ \\
$>26$ & $>6$ & $>4$ \\
\hline
\end{tabular}

Fonte: CHERNICHARO, (2016).

O volume total do reator foi obtido pela Equação (2):

$$
V_{\text {REATOR }}=D Q O_{L O} . T D H
$$

Onde tem-se os seguintes parâmetros:

$V_{R E A T O R}$ - Volume total do reator $\left(\mathrm{m}^{3}\right)$;

$D Q O_{L O}$ - Carga média de DQO $(\mathrm{mg} / \mathrm{L})$;

$T D H$ - Tempo de retenção hidráulico (h).

O simulador possibilita que o volume do reator seja personalizado e, caso esse volume seja menor que o volume do afluente de vinhaça, haverá a modularização dos reatores, ou seja, o sistema passa a considerar que serão utilizados vários reatores para suportar o volume de vinhaça.

b) Cálculo da carga orgânica volumétrica (COV) e da carga hidráulica volumétrica (CHV)

A Equação (3) permite o cálculo da Carga Orgânica Volumétrica (COV), de acordo com Chernicharo (2016):

$$
C O V=\frac{Q \cdot S}{V}
$$

Onde tem-se que:

COV - Carga orgânica volumétrica $\left(\mathrm{kgDQO} / \mathrm{m}^{3} / \mathrm{dia}\right)$;

$Q$ - Vazão ( $\left.\mathrm{m}^{3} / \mathrm{dia}\right)$;

$S$ - Concentração de substrato afluente $\left(\mathrm{kgDQO} / \mathrm{m}^{3}\right)$;

$V$ - Volume total do reator $\left(\mathrm{m}^{3}\right)$.

A Equação (4) permite o cálculo da carga hidráulica volumétrica (CHV):

$$
C H V=\frac{Q}{V}
$$

Onde tem-se que:

$C H V$ - Carga hidráulica volumétrica $\left(\mathrm{m}^{3} / \mathrm{m}^{3}\right.$. dia);

$Q-$ Vazão $\left(\mathrm{m}^{3} / \mathrm{dia}\right)$;

$V-$ Volume do reator $\left(\mathrm{m}^{3}\right)$;

A velocidade superficial pode ser calculada pela Equação (5):

$$
v=\frac{Q}{A}
$$


Onde tem-se que:

$v$ - Velocidade superficial do fluxo $(\mathrm{m} / \mathrm{h})$;

$Q$ - Vazão $\left(\mathrm{m}^{3} / \mathrm{h}\right)$;

$A$ - Área da seção transversal do reator $\left(\mathrm{m}^{2}\right)$.

A velocidade superficial deve estar em consonância com os parâmetros estabelecidos por Chernicharo (2016), apresentados na Tabela 2:

TABELA 2 - Velocidade de acordo com a vazão.

\begin{tabular}{c|c}
\hline Vazão & Velocidade superficial $(\mathrm{m} / \mathrm{h})$ \\
\hline Vazão média & $0,50-0,70$ \\
Vazão máxima & $0,90-1,10$ \\
Picos temporários & $<1,5$ \\
\hline
\end{tabular}

Fonte: CHERNICHARO, (2016).

\section{c) Cálculo da eficiência de remoção de DQO e DBO}

A estimativa da eficiência de remoção de DQO pode ser obtida através da Equação (6), conforme com Chernicharo (2016):

$$
E_{D Q O}=100 .\left(1-0,68 . T D H^{-0,35}\right)
$$

Nessa equação tem-se os seguintes termos:

$E_{D Q O}$ - Eficiência do reator UASB em termos de remoção de DQO (\%);

$T D H$ - Tempo de retenção hidráulica (h);

0,68 e - 0,35 são constantes empíricas da equação.

Para cálculo da eficiência de remoção de DBO do sistema, Chernicharo (2016) sugere o uso da Equação (7):

$$
E_{D B O}=100\left(1-0,7 . T D H^{-0,5}\right)
$$

Nessa Equação tem-se:

$E_{D B O}$ - Eficiência do reator UASB em termos de remoção da DBO (\%);

$T D H$ - Tempo de retenção hidráulica;

0,7 e - 0,5 são constantes empíricas da equação.

Para uma estimativa da concentração de DQO e de DBO no efluente final pode-se usar a Equação (8):

$$
S=S_{O}-\frac{E . S_{O}}{100}
$$

Onde os termos são:

$S$ - Concentração de DQO ou de DBO efluente $(\mathrm{mg} / \mathrm{L})$;

$S_{O}$ - Concentração de DBO ou DQO do afluente $(\mathrm{mg} / \mathrm{L})$;

$E$ - Eficiência de remoção de DQO ou de DBO (\%).

\section{d) Cálculo da produção de biogás}

A Equação (9), conforme descrita por Chernicharo (2016), pode ser usada para calcular a conversão de DQO em gás metano: 


$$
D Q O_{C_{4}}=Q_{\text {med }}\left(S_{O}-S\right)-Y_{a b s} Q_{\text {med }} S_{O}
$$

Onde os termos que aparecem são:

$\mathrm{DQO}_{\mathrm{CH}_{4}}$ - Carga média de DQO $(\mathrm{mg} / \mathrm{L})$

$Q_{\text {med }}$ - Vazão média do afluente $\left(\mathrm{m}^{3} / \mathrm{s}\right)$;

$S_{O}$ - Concentração de DQO do afluente inicial $(\mathrm{mg} / \mathrm{L})$;

$S$ - Concentração de DQO do efluente $(\mathrm{mg} / \mathrm{L})$;

$Y_{a b s}-$ Coeficiente de produção de sólidos $(\mathrm{mg} / \mathrm{L})$.

A conversão da massa de metano ( $\left.\mathrm{kg} D Q O_{C_{4}} / \mathrm{dia}\right)$ em produção volumétrica de metano $\left(\mathrm{m}^{3} \mathrm{CH}_{4} /\right.$ dia) pode ser feita através do uso das Equações (10) e (11), sugerida em Chernicharo (2016):

$$
\begin{gathered}
Q_{\mathrm{CH}_{4}}=\frac{D Q O_{\mathrm{CH}_{4}}}{K(t)} \\
K(t)=\frac{P . \beta}{R T}
\end{gathered}
$$

Nessas equações os termos são:

$Q_{\mathrm{CH}_{4}}$ - Produção volumétrica de metano ( $\left.\mathrm{m}^{3} / \mathrm{dia}\right)$;

$K(t)$ - Fator de correção para a temperatura operacional do reator $\left(\mathrm{kgDQO} / \mathrm{m}^{3}\right)$;

$P$ - Pressão atmosférica (1 atm);

$\beta$ - DQO correspondente a um mol de $\mathrm{CH}_{4}(64 \mathrm{gDQO} / \mathrm{mol})$;

$R$ - Constante dos gases (atm. L/mol. K);

$T$ - Temperatura operacional do reator $(\mathrm{K})$.

A avaliação da produção de biogás é feita pela estimativa do percentual de metano no biogás. Chernicharo (2016) adota um valor de $75 \%$ de metano no biogás.

\section{e) Planejamento estatístico}

Para o estudo da produção de biogás, optou-se por analisar a influência de quatro variáveis: DQO, temperatura (T), tempo de retenção hidráulica (TDH) e vazão (Q). Inicialmente, foram simulados valores referentes a um planejamento fatorial a dois níveis, $2^{\mathrm{K}}$, conforme descrito por Barros Neto et al. (2010), em que $\mathrm{K}$ representa o número de variáveis do sistema, tomadas a dois níveis, totalizando 16 experimentos. A principal finalidade desse planejamento experimental é determinar quais das variáveis selecionadas exercem significativa influência na produção de biogás. A Tabela 3 mostra os dois valores utilizados na simulação.

\begin{tabular}{|c|c|c|}
\hline Variáveis & Nível (+) & Nível (-) \\
\hline $\mathrm{T}\left[{ }^{\circ} \mathrm{C}\right]$ & 89 & 65 \\
\hline $\mathrm{DQO}[\mathrm{mg} / \mathrm{L}]$ & 97400 & 9200 \\
\hline VAZÃO [m³/dia] & 1909 & 530 \\
\hline $\mathrm{TDH}[\mathrm{h}]$ & 17 & 5 \\
\hline
\end{tabular}

TABELA 3 - Valores de máximo e mínimo das variáveis nos experimentos.

Fonte: Elaborada pelos autores, (2016). 
Foi utilizada a matriz do planejamento fatorial $2^{4}$ da Tabela 4 :

TABELA 4 - Matriz do planejamento fatorial $2^{4}$.

\begin{tabular}{c|c|c|c|c}
\hline Experimento & TDH & DQO & Q & T \\
\hline & & & & \\
\hline 1 & - & - & - & - \\
\hline 2 & + & - & - & - \\
\hline 3 & - & + & - & - \\
\hline 4 & + & + & - & - \\
\hline 5 & - & - & + & - \\
\hline 6 & + & - & + & - \\
\hline 7 & - & + & + & - \\
\hline 8 & + & + & + & - \\
\hline 9 & - & - & - & + \\
\hline 10 & + & - & - & + \\
\hline 11 & - & + & - & + \\
\hline 12 & + & + & - & + \\
\hline 13 & - & - & + & + \\
\hline 14 & + & - & + & + \\
\hline 15 & - & + & + & + \\
\hline 16 & + & + & + & + \\
\hline Fon
\end{tabular}

Fonte: Elaborada pelos autores, (2016).

\section{RESULTADOS E DISCUSSÃO}

As características físico-químicas da vinhaça, empregada para a simulação da geração do biogás, foram baseadas no trabalho desenvolvido por Previtali (2011). A Tabela 5 contém os valores utilizados como parâmetros e a quantidade de biogás que foi produzida. O TDH usado na simulação foi de 7 horas.

TABELA 5 - Simulação da produção de biogás com TDH de 7 horas.

\begin{tabular}{l|c|c|c}
\hline \multirow{2}{*}{ Descrição } & \multicolumn{3}{|c}{ Concentrações } \\
\cline { 2 - 4 } & Mínimo & Média & Máximo \\
\hline Dados do Processo & 530 & 1909 & 4128 \\
\hline Vazão [m ${ }^{3} /$ dia] & 6680 & 16949 & 75330 \\
\hline Caracterização da Vinhaça & 28450 & 97400 \\
\hline DBO [mg/L] & 9200 & 89 & 110 \\
\hline DQO [mg/L] & 65 & \\
\hline Temperatura [ $\left.{ }^{\circ} \mathrm{C}\right]$ & Simulação \\
\hline Produção de biogás [m ${ }^{3} /$ dia] & 1254,87 & 15071,41 & 113821,62 \\
\hline Fonte: Adaptado de Previtali, $(2011)$.
\end{tabular}

Para os testes de simulação, foram considerados dois cenários. No primeiro cenário, a simulação da geração de biogás para uma vazão de vinhaça de 530 $\mathrm{m}^{3} / \mathrm{dia}$, sendo simulados a geração, considerando as temperaturas de $65^{\circ} \mathrm{C}$ e $89^{\circ} \mathrm{C}$, valores de DQO de $9200 \mathrm{mg} / \mathrm{Le} 97400 \mathrm{mg} / \mathrm{L}$ e tempos de retenção hidráulica de $5 \mathrm{~h}$, $11 \mathrm{~h}$ e $17 \mathrm{~h}$. Os resultados da simulação do primeiro cenário são apresentados na Tabela 6. 
TABELA 6 - Simulação da produção de biogás com vazão $530 \mathrm{~m}^{3} /$ dia.

\begin{tabular}{cc|c|c}
\hline DQO [mg/L] & TDH [5 h] & TDH [11h] & TDH [17h] \\
\hline \multicolumn{4}{c}{$\left(\right.$ Temperatura $\left.65^{\circ} \mathrm{C}\right)$} \\
\hline 9200 & 1133,82 & 1396,58 & 1513,43 \\
\hline 28450 & 3506,21 & 4318,77 & 4680,11 \\
\hline 97400 & 12003,68 & 14785,51 & 16022,58 \\
\hline \multicolumn{4}{c}{ Temperatura [89 8 C] } \\
\hline 9200 & 1218,19 & 1500,51 & 1926,05 \\
\hline 28450 & 3767,14 & 4640,16 & 5028,39 \\
\hline 97400 & 12896,98 & 15885,83 & 17214,95 \\
\hline
\end{tabular}

Fonte: Elaborada pelos autores, (2016).

A Figura 1 mostra as curvas da produção de biogás a partir dos parâmetros estabelecidos para o primeiro cenário.

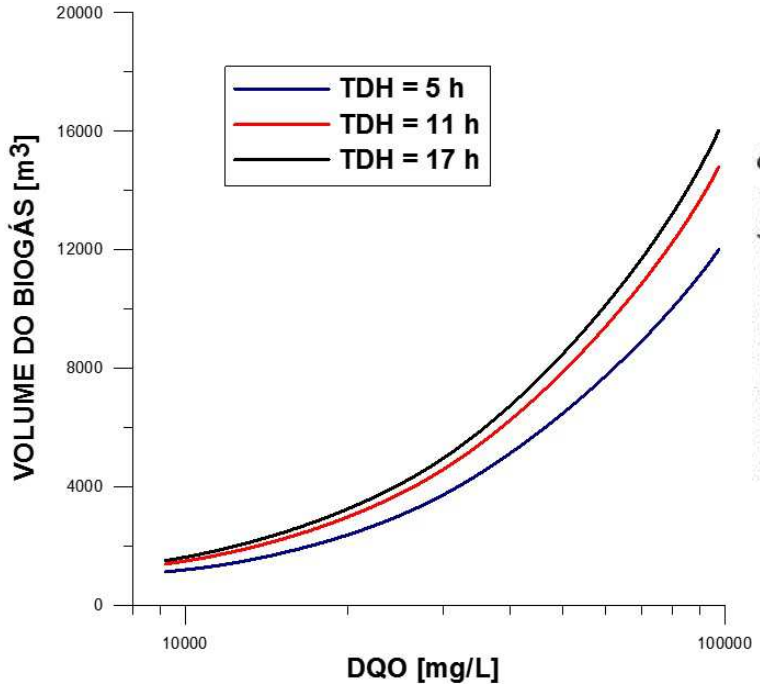

(a)

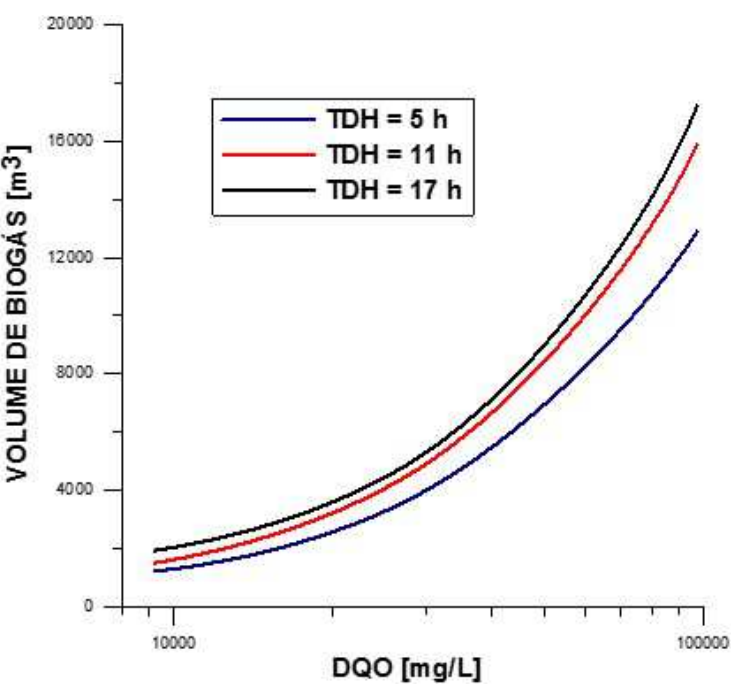

(b)

FIGURA 1 - Produção de biogás na vazão de $530\left[\mathrm{~m}^{3} /\right.$ dia]: a) $\mathrm{T}=65^{\circ} \mathrm{C}$ e b) $\mathrm{T}=$ $89^{\circ} \mathrm{C}$.

FONTE: Elaborada pelos autores, (2016).

Observa-se na FIGURA 1 que um efluente com vazão de $530 \mathrm{~m}^{3} / \mathrm{dia}$, operando a $65^{\circ} \mathrm{C}$ na DQO de $9200 \mathrm{mg} / \mathrm{L}$ e TDH de 11 horas, apresentou uma maior produção de biogás que o efluente de mesma vazão, mesmo DQO e TDH de 5 horas operando na temperatura de $89^{\circ} \mathrm{C}$. Este resultado pode ser uma evidência da interação entre o TDH e a temperatura, mostrando que um aumento no TDH de $5 \mathrm{~h}$ para $11 \mathrm{~h}$ é mais significativo que um aumento na temperatura em termos da produção de biogás. Os resultados apresentados por Tietz et al. (2014), que estudaram a influência da temperatura na produção de biogás, também corroboram que o TDH pode alterar de forma significativa o volume de biogás produzido no reator UASB. Uma melhor avaliação da interação entre a temperatura e o TDH poderia ser estudada com um planejamento fatorial a 3 níveis, onde um valor intermediário das variáveis é adicionado na matriz dos experimentos, possibilitando uma análise mais detalhada (TIETZ et al., 2014).

Destaca-se que para efluentes com mesma vazão, mesma DQO, mesmo TDH e com temperaturas diferentes (Figura 1), nota-se que um aumento na temperatura 
provoca um incremento de cerca de $7 \%$ na produção de biogás. Este resultado pode indicar que a produção de biogás é influenciada pela variabilidade da temperatura da vinhaça. Morell et al. (2015) mostraram que a temperatura influencia a produção de biogás, possibilitando o aproveitamento energético da vinhaça.

No segundo cenário para simulação, a vazão de vinhaça foi aumentada para $1909 \mathrm{~m}^{3} /$ dia. Os valores de temperatura, DQO e TDH foram os mesmos do primeiro cenário. O resultado da simulação do segundo cenário mostrou o mesmo comportamento do primeiro cenário, com o aumento da produção de biogás proporcional ao aumento da vazão. Os resultados dessa simulação estão apresentados na Tabela 7.

TABELA 7 - Simulação da produção de biogás com vazão de $1909 \mathrm{~m}^{3} /$ dia.

\begin{tabular}{c|c|c|c}
\hline DQO $[\mathrm{mg} / \mathrm{L}]$ & TDH $[5 \mathrm{~h}]$ & TDH [11h] & TDH [17h] \\
\hline \multicolumn{4}{c}{$\left(\right.$ Temperatura $\left.65^{\circ} \mathrm{C}\right)$} \\
\hline 9200 & 4083,88 & 5030,32 & 5451,19 \\
97400 & 12628,97 & 15555,70 & 16857,21 \\
& 43235,99 & 53255,73 & 57711,50 \\
\hline 9200 & Temperatura $\left.89^{\circ} \mathrm{C}\right)$ \\
28450 & 4387,80 & 5404,66 & 5856,86 \\
97400 & 13566,97 & 16713,34 & 18111,70 \\
& 46453,45 & 57218,95 & 62006,31 \\
\hline
\end{tabular}

Fonte: Elaborado pelos autores, 2016.

Na FIGURA 2 estão apresentados os resultados da produção de biogás a partir dos parâmetros estabelecidos para o segundo cenário.

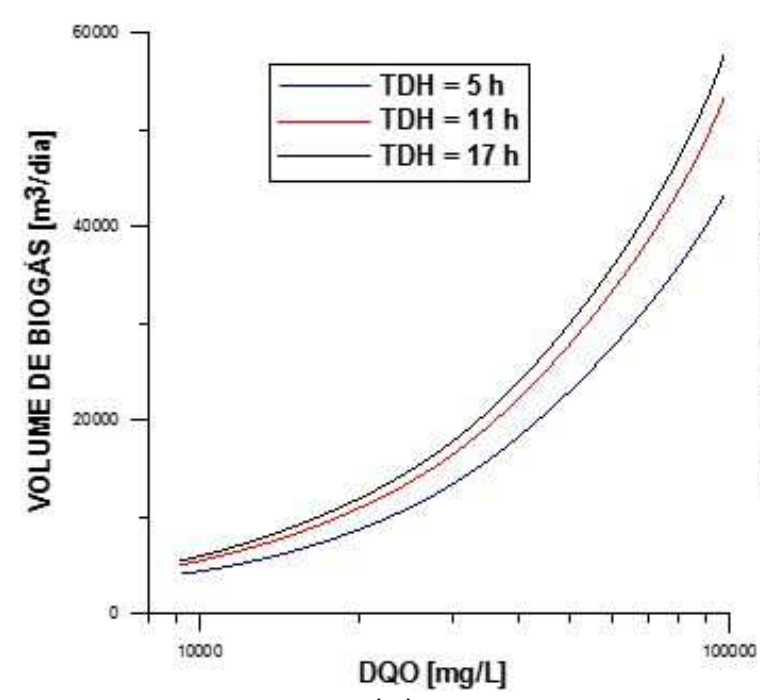

(a)

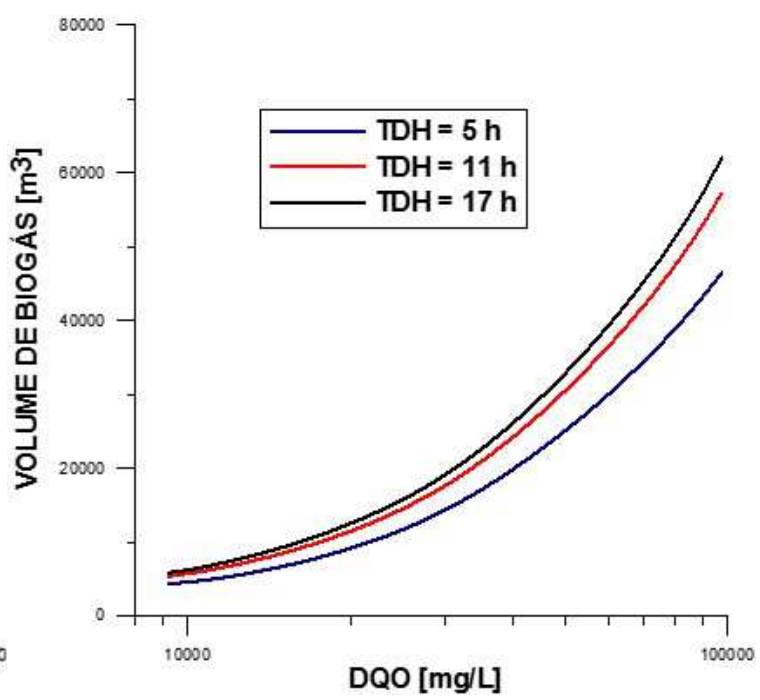

(b)

FIGURA 2 - Produção de biogás na vazão de 1909 [m³/dia]: a) $\mathrm{T}=65^{\circ} \mathrm{C} \mathrm{e} \mathrm{b)} \mathrm{T}=$ $89^{\circ} \mathrm{C}$.

Fonte: Elaborada pelos autores, (2016).

A Tabela 8 mostra a influência das variáveis no volume de biogás produzido. 
TABELA 8 - Matriz do planejamento fatorial.

\begin{tabular}{c|c|c|c|c|c}
\hline EXP & TDH & DQO & Q & T & $\begin{array}{c}\text { VOLUME DE } \\
\text { BIOGÁS [m }\end{array}$ \\
\hline 1 & - & - & - & - & 1133,82 \\
\hline 2 & + & - & - & - & 1396,58 \\
\hline 3 & - & + & - & - & 3506,11 \\
\hline 4 & + & + & - & - & 4318,77 \\
\hline 5 & - & - & + & - & 4083,88 \\
\hline 6 & + & - & + & - & 5032,32 \\
\hline 7 & - & + & + & - & 12628,97 \\
\hline 8 & + & + & + & - & 15555,70 \\
\hline 9 & - & - & - & + & 1218,19 \\
\hline 10 & + & - & - & + & 1500,51 \\
\hline 11 & - & + & - & + & 3767,14 \\
\hline 12 & + & + & - & + & 4640,16 \\
\hline 13 & - & - & + & + & 4387,80 \\
\hline 14 & + & - & + & + & 5404,66 \\
\hline 15 & - & + & + & + & 13568,80 \\
\hline 16 & + & + & + & + & 16713,34 \\
\hline
\end{tabular}

Fonte: Elaborada pelos autores, 2016.

Analisando a influência do TDH, quando ocorre aumento dessa variável, passando de (-) para (+), com todas as demais variáveis analisadas no mesmo valor, caso dos experimentos 1 e 2 e experimentos 15 e 16, há aumento da resposta, que é o volume de biogás. Isto significa que a variável TDH tem influência no volume de gás produzido. Resultados semelhantes foram encontrados em trabalhos experimentais, (TIETZ et al., 2014).

Houve aumento da resposta em relação à variável DQO, quando são comparados os volumes do gás produzido nos experimentos 1 e 3 e nos experimentos 14 e 16. Logo, a variável DQO também exerce uma influência no volume de biogás produzido, conforme descrito em Rizvi et al. (2015). Continuando com essa análise, verifica-se um aumento da resposta em relação à variável $Q$, quando se compara o volume do gás produzido nos experimentos 1 e 5 , e nos experimentos 12 e 16. Isto evidencia que a vazão $(Q)$ tem influência no volume de biogás produzido, (RIZVI et al., 2015).

Para análise da influência da temperatura $(T)$ na resposta, os resultados dos experimentos 1 e 9 e experimentos 8 e 16 mostram que há um aumento no volume de gás, indicando que a variável T também influencia o volume de biogás produzido, conforme Rizvi et al. (2015). Por intermédio da análise estatística empregada neste trabalho, observa-se que todas as variáveis selecionadas exercem influência no volume de biogás produzido.

\section{CONCLUSÃO}

Neste trabalho foram realizadas simulações a partir de um conjunto de equações que descrevem o comportamento da biodigestão anaeróbia da vinhaça em um reator UASB, usando um planejamento estatístico fatorial $2^{4}$. Os resultados obtidos mostraram que todas as variáveis analisadas, DQO, temperatura, TDH e vazão, têm influência na produção de biogás. Destaca-se que um aumento na temperatura da vinhaça de $65^{\circ} \mathrm{C}$ para $89^{\circ} \mathrm{C}$, resultou em um aumento de cerca de 
$7 \%$ no volume de biogás produzido, mostrando que a produção de biogás pode ser influenciada pela variabilidade da temperatura. Um aumento na DQO da vinhaça de $9200 \mathrm{mg} / \mathrm{L}$ para $97400 \mathrm{mg} / \mathrm{L}$ resultou em um aumento significativo no volume de biogás produzido, indicando aumento na conversão do biogás. Com o aumento na vazão de vinhaça de $530 \mathrm{~m}^{3} /$ dia para $1909 \mathrm{~m}^{3} /$ dia houve também aumento significativo no volume de biogás produzido, possivelmente porque há mais massa entrando no sistema. Já um aumento no TDH de $5 \mathrm{~h}$ para $17 \mathrm{~h}$ resultou em um aumento de cerca de $23 \%$ no volume de biogás, pois implica maior tempo de contato da massa no reator. Essa metodologia apresenta possibilidade de aplicação prática, uma vez que os resultados obtidos na simulação computacional estão em consonância com dados experimentais da literatura, mostrando que a simulação é uma ferramenta importante para avaliação do tratamento da vinhaça em uma indústria sucroalcooleira.

\section{REFERÊNCIAS}

AMATO, F. Nível dos reservatórios do sudeste e centro-oeste é o menor desde 2001. G1, Brasília, 2014. Disponível em: <http://goo.gl/WiRFQo>. Acesso em: 29 abril de 2016.

BARROS NETO, B.; SCARMINIO, I. S.; BRUNS, R. E. Como fazer experimentos: aplicações na ciência e na indústria. $4^{\mathrm{a}}$ ed. Porto Alegre: Bookman, 2010. 414p. ISBN: 9788577806522.

CANNEYT, M. V.; KLAMPFL, F. Free Pascal, $2^{a}$ ed. Computer \& Literatur Verlag GmbH, ISBN 978-3936546729, 393654672X, 2012.

CHERNICHARO, C. A. de L. Reatores anaeróbicos. $2^{\mathrm{a}}$ ed. ampliada e atualizada. Belo Horizonte: DESA - UFMG, 2016, v. 5, 379 p. ISBN 9788542301724.

LUCON, O.; GOLDEMBERG, J. Crise financeira, energia e sustentabilidade no Brasil. Estud. av, São Paulo, v. 23, $\mathrm{n}^{\circ}$ 65, 2009. Disponível em: <http://goo.gl/zQIKdQ>. Acesso em: 29 abril de 2016.

MORAES, B. S.; JUNQUEIRA, T. L.; PAVANELLO, L. G.; CAVALETT, O.; MANTELATTO, P. E.; BONOMI, A.; ZAIAT, M. Anaerobic digestion of vinasse from sugar cane biorefineries in Brazil from energy, environmental, and economic perspectives: profit or expense? Applied Energy, vol. 113, pp. 825-835, january 2014. DOI: https://doi.org/10.1016/j.apenergy.2013.07.018.

MORELL, P. O.; SANTOS, V. T.; STREMEL, D. P. Influência da temperatura sobre a produção de biogás utilizando a biodigestão da vinhaça, V SIMBBTEC - Simpósio de Bioquímica e Biotecnologia, 05 a 07 de agosto de 2015, Londrina-PR.

PREVITALI, N. R.; Uso de vinhaça para fertirrigação, 2011. Monografia (Graduação em Curso de Tecnologia em Biocombustíveis) - Faculdade de Tecnologia de Araçatuba, Araçatuba, SP.

REIN, P. Cane Sugar Engineering, Verlag Dr. Albert Bartens KG. Berlim, 2017. 
RIZVI, H.; AHMAD, N.; ABBAS, F.; BUKHARI, I. H.; YASAR, A.; ALI, S.; YASMEEN, T.; RIAZ, M. Start-up of UASB reactors treating municipal wastewater and effect of temperature/sludge age and hydraulic retention time (HRT) on its performance, Arabian Journal of Chemistry, v. 8, pp. 780-786, 2015.

DOI: http://dx.doi.org/10.1016/j-arabjc.2013.12.016.

RODRIGUES, A.; SANTOS, R. F.; AVACI, A. B.; ROSA, H. A.; CHAVES, L. I.; GASPARIN, E. Estimativa do potencial de geração de energia elétrica a partir da vinhaça. Acta Iguazu, Cascavel, v. 1, $\mathrm{n}^{\circ}$ 2, p. 80-93, 2012. Disponível em: erevista.unioeste.br/index.php/actaiguazu/article/view/7040/5192. Acesso em 14 maio de 2016.

TIETZ, C. M.; ZENATTI, D. C.; FEIDEN, A.; LUPATINI, K. N.; CORRÊIA, A. F. Influência da temperatura na produção de biogás a partir de dejetos da bovinocultura de leite. Revista Brasileira de Energias Renováveis, v. 3, p. 80-96, 2014.

DOI: http://dx.doi.org/10.5380/rber.v3i4.

UNIÃO DA INDÚSTRIA DA CANA DE AÇÚCAR (ÚNICA). Moagem de cana de açúcar e produção de açúcar e etanol: safra 2015/2016. Disponível em: <http://goo.gl//A3vim>. Acesso em 15 maio 2017. 